\title{
Variation in Susceptibility to Benznidazole in Isolates Derived from Trypanosoma cruzi Parental Strains
}

\author{
VM Veloso, CM Carneiro*, MJO Toledo, M Lana*, E Chiari**, WL Tafuri, \\ MT Bahia/ ${ }^{+}$
}

\begin{abstract}
Departamento de Ciências Biológicas, ICEB *Departamento de Análises Clínicas, Escola de Farmácia, Universidade Federal de Ouro Preto, Campus Universitário, Morro do Cruzeiro, 35400-000 Ouro Preto, MG, Brasil **Departamento de Parasitologia, ICB, Universidade Federal de Minas Gerais, MG, Brasil
\end{abstract}

In this work, the susceptibility to benznidazole of two parental Trypanosoma cruzi strains, Colombian and Berenice-78, was compared to isolates obtained from dogs infected with these strains for several years. In order to evaluate the susceptibility to benznidazole two groups of mice were infected with one of five distinct populations isolated from dogs as well as the two parental strains of $\mathrm{T}$. cruzi. The first group was treated with benznidazole during the acute phase and the second remained untreated controls. The animals were considered cured when parasitological and serological tests remained persistently negative. Mice infected with the Colombian strain and its isolates Colombian (A and $B$ ) did not cure after treatment. On the other hand, all animals infected with Berenice-78 were cured by benznidazole treatment. However, 100\%, 50\% and $70 \%$ of cure rates were observed in animals infected with the isolates Berenice- $78 \mathrm{~B}, C$ and $D$, respectively. No significant differences were observed in serological profile of infected control groups, with all animals presenting high antibody levels. However, the ELISA test showed differences in serological patterns between mice inoculated with the different $\mathrm{T}$. cruzi isolates and treated with benznidazole. This variability was dependent on the T. cruzi population used and seemed to be associated with the level of resistance to benznidazole.

Key words: chemotherapy - drug susceptibility - Trypanosoma cruzi - benznidazole

Trypanosoma cruzi, the agent of Chagas disease, exhibits considerable biological variability (Carneiro et al. 1991, Andrade \& Magalhães 1997). Studies using cloned or uncloned populations, reinforce the heterogeneity of the parasite and demonstrate that, in general, strains of T. cruzi are composed of subpopulations with distinct characteristics (Postan et al. 1986, Finley \& Dvorak 1987). Several authors have extensively investigated the correlation between $T$. cruzi genetic background and the different clinical forms of Chagas disease, as well as biological characteristics, such as virulence, pathogenicity and susceptibility to drugs (Revollo et al. 1998, Andrade 1999).

Filardi and Brener (1987) and Toledo et al. (1997) described the existence of strains naturally resistant and non-resistant to benznidazole and nifurtimox. Natural resistance to nitro-derivates has

This investigation received financial support from Fapemig, CNPq and Ufop.

${ }^{+}$Corresponding author. Fax: +55-31-3559.1680. E-mail: mtbahia@cpd.ufop.br

Received 14 November 2000

Accepted 4 July 2001 been suggested as an important factor in explaining the low rates of cure detected in treated patients (Murta \& Romanha 1998). Several authors have shown that resistance of $T$. cruzi strains to benznidazole and nifurtimox increased when parasites were isolated from mice previously treated with these same drugs (Marretto \& Andrade 1994, Murta \& Romanha 1998). The authors suggest that the initial treatment eliminated the sensitive parasites, preserving the resistant ones, which multiplied and dominated the population. In this manner, the imposition of natural and artificial pressure can result in the selection of a subset of the population.

If the strains of $T$. cruzi present clonal structure, based on the existence of clonal lines without sexual interactions (Tibayrenc \& Ayala 1988), it is possible to think that clones with variable degrees of drug susceptibility presented among the whole circulating population would show different growth rates in the host. Consequently, genetic characteristics of the host could favor the development of certain clones within the host, which could reflect differences in the susceptibility to drugs. To confirm this hypothesis, the susceptibility to benznidazole of different isolates of $T$. cruzi, originated from dogs infected 2, 7, 8 and 17 years before, were comparatively studied in mice with the parental Colombian and Berenice-78 strains. 


\section{MATERIALS AND METHODS}

T. cruzi strains and populations isolated from dogs - The parental strains Colombian (Col) - $T$. cruzi I (Federici et al. 1964), resistant to benznidazole (Filardi \& Brener 1987) and Berenice-78 (Be-78) - T. cruzi II (Lana \& Chiari 1986), 100\% susceptible to benznidazole (Toledo et al. 1995), were used as references.

T. cruzi stocks were isolated from different dogs after 8 and 17 years of infection with Col strain (Col $\mathrm{A}$ and $\mathrm{B}$, respectively) and with Be-78 after 7 (Be$78 \mathrm{~B}$ and $\mathrm{C}$ ) and 2 (Be-78 D) years of infection.

\section{Experimental conditions}

Mice infection - For each strain or stock of $T$. cruzi, 12 Swiss outbreed mice (30 days old, 18-20 g weight) were infected by intraperitoneal route with $5 \times 10^{3}$ blood trypomastigotes, obtained from infected mice. Six mice were submitted to treatment with benznidazole (N-benzyl-2-nitro-1-imidazolacetamide - Roche Company), and six remained as untreated infected controls. The experiments were repeated when the percentage of cure was different between the parental strains and their isolates.

Treatment schedules - Animals were treated after the detection of patent parasitaemia, approximately four days post-inoculation. Benznidazole was administered in a suspension made with $4 \%$ arabic gum (Sigma) by oral doses of $100 \mathrm{mg}$ of benznidazole $/ \mathrm{kg}$, for 20 consecutive days. Animals were considered cured when both parasitological (fresh blood examination, hemoculture and PCR) and serological (ELISA) tests were negative.

\section{Parameters evaluated}

Parasitaemia and mortality - The parasitaemia was followed from the 4th day of infection until the negativation of the parasitaemia by fresh blood collected from the mouse's tail and the number of parasites was estimated as described by Brener (1962). Curves were plotted using the mean of the parasitaemia from six mice. Mortality rate was expressed as a percentage of accumulated deaths within the period of 180 days after the inoculation.

Hemoculture - Mice were bled from the orbital venous sinus 30 and 180 days after the end of treatment. The blood was split into two tubes containing $5 \mathrm{ml}$ of Liver Infusion Tryptose medium (Filardi $\&$ Brener 1987). The tubes were incubated at $28^{\circ} \mathrm{C}$ for 30-90 days and microscopically examinated for the presence of parasites 30,60 and 90 days later.

PCR assay - PCR were performed only in samples from animals with negative hemoculture. Mice were bled from the orbital venous sinus and $200 \mu \mathrm{l}$ of blood were collected. The sample were immediately mixed with $400 \mu \mathrm{l}$ of $6 \mathrm{M}$ guanidine HCL/0.2 M EDTA solution (Ávila et al. 1991) and stored at room temperature for one week. This mixture was boiled for $7 \mathrm{~min}$ to break the minicircles (Britto et al. 1993). DNA extraction was performed according to Wincker et al. (1994), but using $40 \mu \mathrm{g}$ of Glycogen (Boeringer Mannheim) to precipitate the DNA. The pellets obtained were resuspended in $40 \mu \mathrm{l}$ of distilled sterile water and stored at $60^{\circ} \mathrm{C}$ for $1 \mathrm{~h}$. PCR conditions were described by Gomes et al. (1998). The PCR mixture contained $2 \mu$ of DNA solution, $10 \mathrm{mM}$ Tris- $\mathrm{HCl}$ (pH 9.0), $75 \mathrm{mM} \mathrm{KCl}, 3.5$ $\mathrm{mM} \mathrm{MgCl} 2,0.1 \%$ Triton X-100, $0.2 \mathrm{mM}$ each dATP, dCTP, dGTP and dttp (Sigma Co. Ltd.), 20 pmol of S 35 ( 5' A A A T A AT G T A C G G G ( T/G) GAGATGCATGA3') and S36(5'GGGTTCGATT GGGGTTGGTGT3') primers (Ávila et al. 1990), 1.0 unit of Taq DNA polimerase (GIBCO), and $40 \mu \mathrm{l}$ with water. The reaction mixtures were overlaid with $30 \mu \mathrm{l}$ of mineral oil and subjected to 35 cycles of amplification in a Research Programmable Thermal Controller (MinCycler TM). The temperature profile were $95^{\circ} \mathrm{C}$ for $1 \mathrm{~min}$ for denaturation with a longer initial time of $5 \mathrm{~min}$ at $95^{\circ} \mathrm{C}, 65^{\circ} \mathrm{C}$ for $1 \mathrm{~min}$ for primer annealing, and $72^{\circ} \mathrm{C}$ for $10 \mathrm{~min}$ to extend the annealed primers. Five microliters of PCR products were analyzed by electrophoresis on a $6 \%$ polyacrylamide gel and visualized by staining with silver salts (Santos et al. 1993).

Serological profile - Ten microliters of blood were collected from mice tails every two weeks for three months and monthly thereafter until seven months post-infection in $90 \mu \mathrm{l}$ de $\mathrm{PBS}, \mathrm{pH}$ 7.2. The sera obtained were stored at $-20^{\circ} \mathrm{C}$, and samples from treated and untreated mice were tested in parallel. ELISA test were performed according to Voller et al. (1976). Peroxidase conjugated goat anti-mouse $\mathrm{IgG}$ (Sigma) was used. The cut-off was determined by using the mean absorbance from ten uninfected animals plus two standard deviations.

\section{RESULTS}

Parasitological cure - The Table shows the percentage of cure induced by benznidazole after long-term treatment of different groups of mice infected with each parental strains and their isolates from dogs. Animals infected with $\mathrm{Col}$ strain and isolates $\mathrm{Col} \mathrm{A}$ and $\mathrm{Col} \mathrm{B}$ did not respond to treatment with benznidazole. On other hand, mice infected with Be-78 strain showed $100 \%$ of cure after treatment, whereas mice infected with their isolates Be-78B, C and D) displayed different spectra of susceptibility to benznidazole, with $100 \%, 50 \%$ and $70 \%$ of cure rates, respectively. The evaluation of the presence of specific antibodies in the sera of these animals after treatment correlated with the parasitological findings.

The effect of benznidazole on the reduction of parasitaemia - Mice infected with Col strain and 
TABLE

In vivo susceptibility to benznidazole of parental strains Colombian (Col) and Berenice-78 (Be-78) and their respective isolates

\begin{tabular}{llcccc}
\hline $\begin{array}{l}\text { Trypanosoma cruzi } \\
\text { population }\end{array}$ & $\begin{array}{c}\text { Experimental } \\
\text { groups }\end{array}$ & $\begin{array}{c}\text { No. } \\
\text { mice }\end{array}$ & $\begin{array}{c}\text { Parasitological tests }^{a} \\
\text { Positive/total }\end{array}$ & $\begin{array}{c}\text { Serological tests } \\
\text { Positive/total }\end{array}$ & $\begin{array}{c}\text { Cure rates } \\
(\%)\end{array}$ \\
\hline Be-78 strain & Treated & 6 & $0 / 6$ & $0 / 6$ & 100 \\
Be-78 B & Untreated & 6 & $6 / 6$ & $6 / 6$ & - \\
& Treated & 6 & $0 / 6$ & $0 / 6$ & 100 \\
Be-78 C & Untreated & 6 & $6 / 6$ & $6 / 6$ & - \\
& Treated & 12 & $5 / 12$ & $6 / 12$ & 50 \\
Be-78 D & Untreated & 12 & $12 / 12$ & $12 / 12$ & - \\
& Treated & 10 & $3 / 10$ & $3 / 10$ & 70 \\
Col strain & Untreated & 12 & $12 / 12$ & $12 / 12$ & - \\
& Treated & 6 & $6 / 6$ & $6 / 6$ & 0 \\
Col-A & Untreated & 6 & $6 / 6$ & $6 / 6$ & - \\
& Treated & 6 & $6 / 6$ & $6 / 6$ & 0 \\
Col-B & Untreated & 6 & $6 / 6$ & $6 / 6$ & - \\
& Treated & 6 & $6 / 6$ & $6 / 6$ & 0 \\
\hline
\end{tabular}

$a$ : hemoculture and PCR; $b$ : ELISA

Col-A isolated showed suppression of parasitaemia during treatment, whereas in animals infected with Col-B isolate this parameter was reduced but not completely suppressed. All mice inoculated with Col strain and $\mathrm{Col}$ (A and B) isolates showed patent parasitaemia on the 7 th day post treatment. Treated animals showed a decrease in parasitaemia levels of 2.5 and 5 times the levels of untreated control (Fig. 1). All mice infected with Be-78 strain and Be78 (B, C and D) showed a suppression of parasitaemia on the first day of treatment onset, which persisted throughout and after the treatment period.

The mortality rate - At 180 days post treatment the mortality rate was $100 \%$ in the control group infected with Col strain and $40 \%$ in the treated group. There was no mortality in treated and untreated mice infected with $\mathrm{Col}(\mathrm{A}$ and $\mathrm{B})$ isolates and $\mathrm{Be}-78$ strain as well as their isolates (Be-78 B, C and D).

Serological profile - $T$. cruzi specific IgG antibodies were detected 20-30 days after infection in sera of infected control groups and all animals displayed high levels of antibodies regardless of the strain or isolate used for inoculation (Figs 2, 3). However differences in the serological pattern among mice infected with different populations of T. cruzi after treatment was detected.

In all animals infected with Col strain, IgG antibodies were detected from one to 10 days post treatment. In animals infected with Col-A the antibody levels were under the cut-off values ( $\mathrm{Abs}=0,233$ ) between 30 and 60 days of infection, raising to con- trol levels thereafter. Antibody levels in treated and untreated animals infected with $\mathrm{Col} \mathrm{B}$ were similar throughout the infection period (Fig. 2).

Similar serological profiles were observed in mice infected with $\mathrm{Be}-78$, and isolates $\mathrm{Be}-78$ that responded to treatment with antibodies levels always under the cut-off value. In all animals infected with Be-78 (C and D), that remained infected post treatment, the antibody levels remained under the cut-off $(0,233)$ until 90 and 120 days after treatment slowly raising afterwards but without reaching the same level of untreated controls (Fig. 3).

\section{DISCUSSION}

Natural resistance of $T$. cruzi to nitro derivates has been described as an important factor to explain the low rates of cure detected in treated chagasic patients (Filardi \& Brener 1987). The authors described the existence of strains that are naturally resistant and non-resistant to benznidazole and nifurtimox.

Relatively few reports have been published concerning the in vivo induction of drug resistance to T. cruzi. Andrade et al. (1977) showed that the resistance to drugs benznidazole and nifurtimox increased when the parasites were isolated from mice previously treated with the same drugs. Regarding this aspect, it is important to mention that the isolates used in this work were obtained from dogs that were not treated, eliminating, in this way, the possibility of influence of the drug on induction of parasite resistance to treatment. 


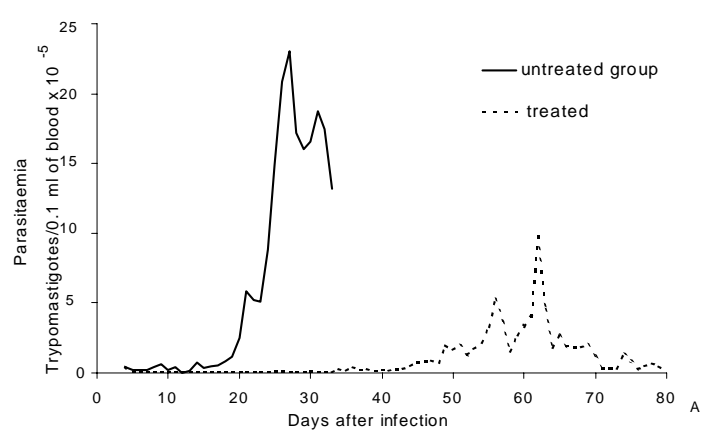

groups inoculated with Col strain and Col-A. The anti- $T$. cruzi antibody production was delayed in mice infected with the parental Col and Col-A while, in mice infected with Col-B, IgG antibodies were detected also during treatment, similar to observed in control untreated groups. Camandaroba (1999) demonstrated the high resistance of Col strain to benznidazole and verified also similar resistance in seven clones of this strain.
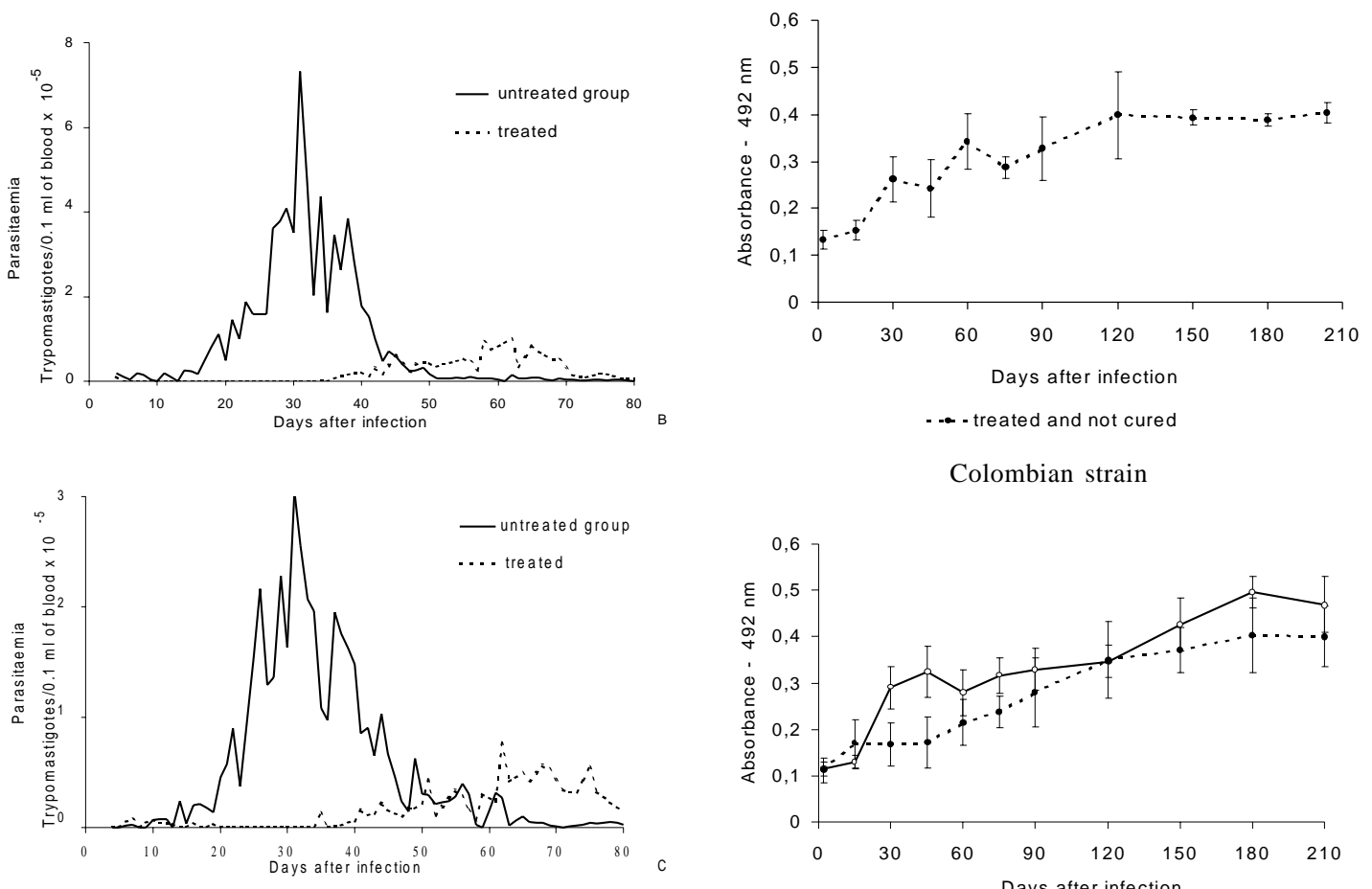

Fig. 1: mean parasitaemia in groups of six Swiss outbreed mice infected with $5 \times 10^{3}$ blood trypomastigotes, intraperitoneal route - A: Colombian parental strain; B: Colombian-A isolate; and C: Colombian-B isolate of Trypanosoma cruzi in animals treated and not treated with benznidazole during the acute phase of the infection.

In this study we observed stability of the resistance to benznidazole in the populations from the Colombian strain isolated of dogs 8 and 17 years after infection. However, the fact of the animals infected with the Col-B isolate presented patent parasitaemia during treatment suggests the presence of a higher proportion of resistant subpopulation to benznidazole in this isolate in relation to the parental strain and Col-A. This supposition is corroborated by analysis of the $T$. cruzi specific IgG profile observed in these mice in relation to the

Colombian strain

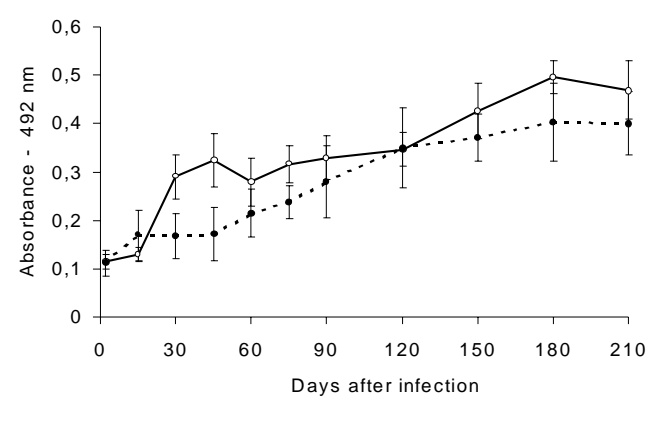

$\multimap$ untreated group $\quad \ldots$... treated and not cured

Colombian - A

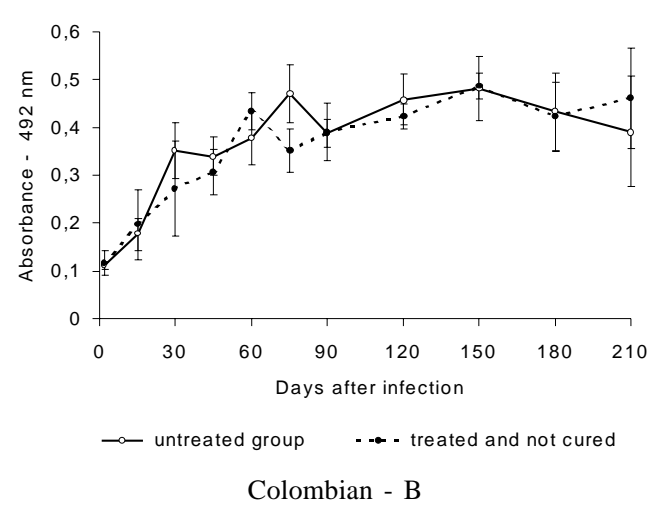

Fig. 2: Trypanosoma cruzi specific IgG antibodies in sera of infected control groups and treated mice infected with Colombian parental strain of T. cruzi and their isolates from dogs (Colombian A and B). 


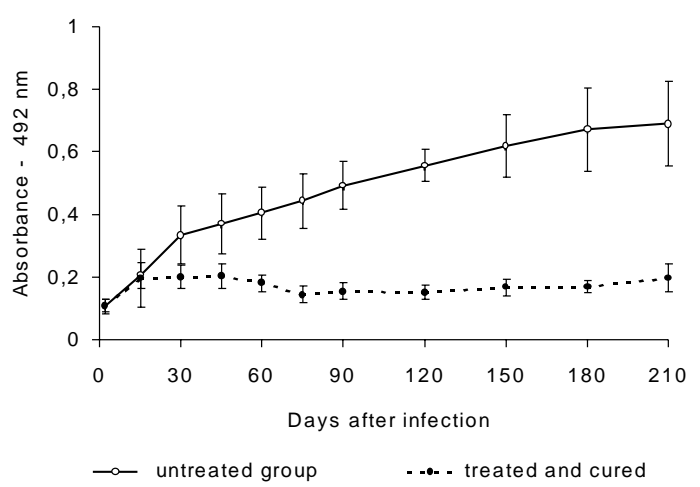

Berenice-78 strain

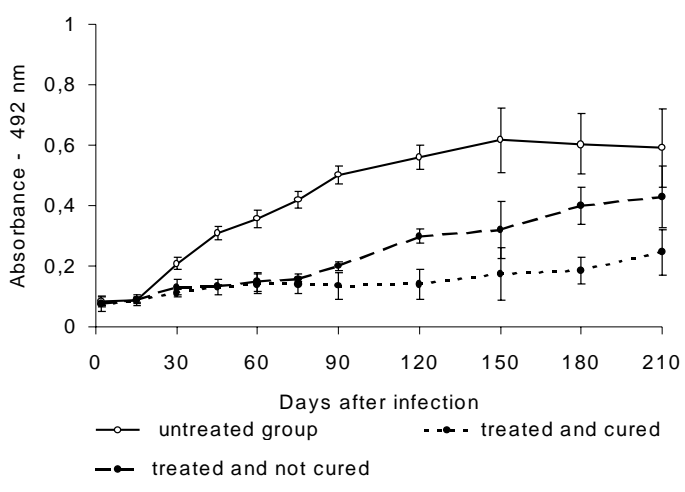

Berenice-78 C

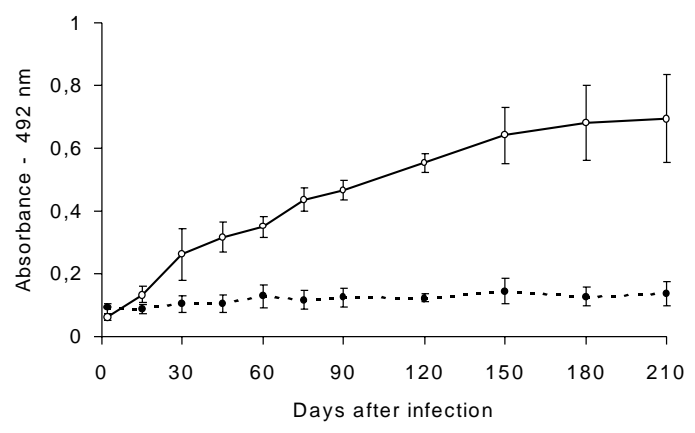

$\multimap$ untreated group $\quad$ - -.- - treated and cured

Berenice-78 B

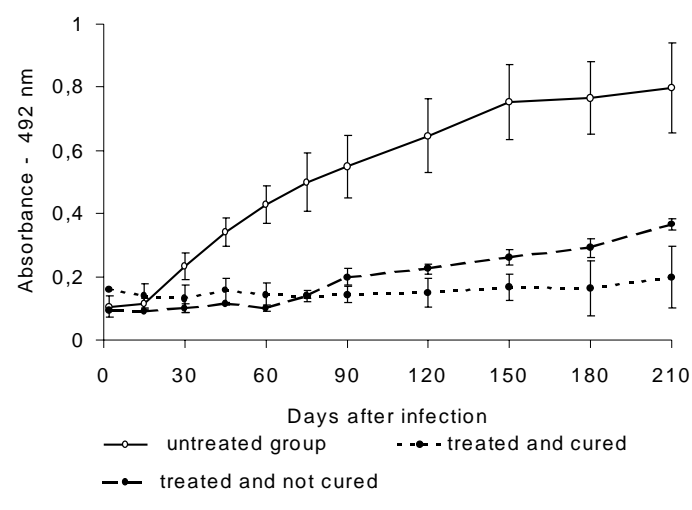

Berenice-78 D

Fig. 3: Trypanosoma cruzi specific IgG antibodies in sera of infected control groups and treated mice infected with Berenice-78 parental strain of T. cruzi and their isolates from dogs (Berenice-78 B, C and D).

Andrade et al. (1977) suggested the selection of resistant parasites to explain the parasite persistence in vertebrate hosts after prolonged treatment. To test this hypothesis Murta and Romanha (1998) investigated the development of drug-resistance of $T$. cruzi $\mathrm{Y}$ strain isolated from mice not cured after treatment with benznidazole or nifurtimox. The authors demonstrate the in vivo selection of a population and clones of $T$. cruzi resistant to benznidazole from the Y strain (50\% resistant to benznidazole) and suggest that the resistance of the strain seems to be related to the sensitive/resistant clone ratio in the population.

The present work, however, shows a different situation since we observed a change of susceptibility to benznidazole in isolates of the Be- 78 strain considered $100 \%$ susceptible (Toledo et al. 1995). Mice inoculated with the isolates (Be-78 C and D) from dogs infected for seven and two years with Be-78 showed susceptibility of 50 and $70 \%$, respectively. These results are difficult to be explained based on the selection of a subset of the population. If within the parental population a clone resis- tant to benznidazole was to be present, the parental Be-78 strain should present some degree of resistance to treatment. Moreover, correlations between the sensibility to benznidazole and nifurtimox and the genetic distance between $T$. cruzi stocks have been described in vitro (Revollo et al. 1988) and in vivo (Toledo et al. 2000). Also, Andrade et al. (1992) revealed $82 \%$ of coincidence between treatment results in patients and mice infected with same strains.

Considering that the genetic characteristic may be one of the factors that modulate the benznidazole resistance/sensibility process, the variation of benznidazole susceptibility observed, specially with Be-78 C, may reflect the genetic plasticity observed in $T$. cruzi demonstrated by several authors. Pacheco and Brito (1999) studying parasite population in mice revealed evidence that polymorphism in minicircles sequences can emerge during infection with a single clone of T. cruzi. MacDaniel and Dvorak (1993) also showed that under stress conditions, or selective pressures, chromossomes and minicircles shown evidences of genetic plasticity 
in T. cruzi and Leishmania. The authors postulate that errors in DNA synthesis or replication may occur. These errors could be lethal or produce organisms with either reduced or enhanced survival potential depending upon the influence of external modulating variables such as the environment. In Plasmodium falciparum the chromosome size polymorphism among different strains is caused by the acquisition and deletion of mainly repetitive elements in a subtelomeric position (Lanzer et al. 1994).

An alternative hypothesis to explain the variability in drug resistance in Be-78 C and D isolates is that drug-resistant mutants arise for genetic exchange. Two studies of multiple T. cruzi isolates from single localities have found some evidence of genetic exchange (Bogliolo et al. 1996, Carrasco et al. 1996). Although clonal propagation may predominate in transmission cycles involving humans, genetic exchange in natural populations might emerge $T$. cruzi strains with new resultant biological properties, such as virulence and drug resistance.

In this study we also demonstrated variability of specific antibody production profile in mice infected with $T$. cruzi populations with different patterns of resistance to benznidazole. The variation of antibody levels observed between mice treated and not cured, apparently related to the parasite resistance to benznidazole, seems to correlate with the decrease of parasitaemia. According to Marretto and Andrade (1994) initial treatment would eliminate the sensitive parasites, leading to a predomination of a resistant population. Our data suggest that the serological profile is related to the sensitive/resistant clone ratio in the population. In mice infected with a $T$. cruzi resistant strain, the suppression of the parasitaemia after treatment is slower and consequently the antigenic stimulation of antibody production is higher.

In this work we demonstrate the alteration in the benznidazole resistance/sensibility characteristic in the populations isolates of dogs infected with Be-78 strains. However, the biochemical mechanism that underlines drug resistance in isolates of this parasite remains to be elucidated.

\section{ACKNOWLEDGEMENTS}

To Dr Luiz Carlos Crocco Afonso for his painstaking care in English corrections.

\section{REFERENCES}

Andrade SG 1999. Trypanosoma cruzi: clonal structure of parasite strains and the importance of principal clones. Mem Inst Oswaldo Cruz 94: 185-187.

Andrade SG, Magalhães JB 1997. Biodemes and zymodemes of Trypanosoma cruzi strains: correlations with clinical data and experimental pathology. Rev Soc Bras Med Trop 30: 27-35.
Andrade SG, Andrade ZA, Figueira RM 1977. Estudo experimental sobre a resistência de uma cepa do Trypanosoma cruzi ao Bay 2502. Rev Inst Med Trop São Paulo 19: 124-129.

Andrade SG, Rassi A, Magalhães JB, Ferrioli Filho F, Luquetti AO 1992. Specific chemotherapy of Chagas disease: a comparison between the response in patients and experimental animals inoculated with the same strain. Trans $R$ Soc Trop Med Hyg 86: 624626.

Ávila H, Gonçalves AM, Nehme NS, Morel CM, Simpson L 1990. Schizodeme analysis of Trypanosoma cruzi stocks from South and Central America by analysis of PCR-amplified minicircle variable region sequences. Mol Biochem Parasitol 42: 175-187.

Ávila HA, Sigman DS, Cohen LM, Millikan RC, Simpson L 1991. Polymerase chain reaction amplification of Trypanosoma cruzi kinetoplast minicircle DNA isolation from whole blood lysates: diagnosis of chronic Chagas' disease. Mol Biochem Parasitol 40: 211-222.

Bogliolo AR, Lauria-Pires L, Gibson WC 1996. Polymorphisms in Trypanosoma cruzi: evidence of genetic recombination. Acta Trop 61: 31-40.

Brener Z 1962. Therapeutic activity and criterion of cure in mice experimentally infected with Trypanosoma cruzi. Rev Inst Med Trop São Paulo 4: 389-396.

Britto C, Cardoso MA, Wincker P, Morel CM 1993. A simple protocol for cleavage of Trypanosoma cruzi kinetoplast DNA present in blood sample and its use in polymerase chain reaction (PCR)-based diagnosis of chronic Chagas' disease. Mem Inst Oswaldo Cruz 88: 171-172.

Camandaroba E 1999. Caracterização clonal da cepa Colombiana do Trypanosoma cruzi: estudo do comportamento biológico, bioquímico e da resposta terapêutica dos clones isolados. Rev Soc Bras Med Trop 32 (Supl. I): 81-82.

Carneiro M, Romanha AJ, Chiari E 1991. Biological characterization of Trypanosoma cruzi strains from different zymodemes and schizodemes. Mem Inst Oswaldo Cruz 86: 387-393.

Carrasco HJ, Frame IA, Valente SA, Miles MA 1996. Genetic exchange as a possible source of genomic diversity in sylvatic populations of Trypanosoma cruzi. Am J Trop Med Hyg 54: 418-424.

Filardi LS, Brener Z 1987. Susceptibility and natural resistance of Trypanosoma cruzi strains to drugs used clinically in Chagas disease. Trans $R$ Soc Trop Med Hyg 81: 755-759.

Finley RW, Dvorak JA 1987. Trypanosoma cruzi: analysis of the population dynamics of heterogeneous mixtures. J Protozool 34: 409-415.

Federici EE, Abelmann WH, Neva FA 1964. Chronic and progressive myocarditis and myositis in $\mathrm{C}_{3} \mathrm{H}$ mice infected with Trypanosoma cruzi. Am J Trop Med Hyg 13: 272-280.

Gomes ML, Macedo AM, Vago AR, Pena SDJ, Galvão LMC, Chiari E 1998. Trypanosoma cruzi: optimization of polymerase chain reaction for detection in human blood. Exp Parasitol 88: 28-33.

Lana M, Chiari E 1986. Caracterização biológica comparativa das cepas Berenice e Berenice-78 de Trypanosoma cruzi isoladas da mesma paciente em 
diferentes períodos. Mem Inst Oswaldo Cruz 81: 247-253.

Lanzer M, de Bruin D, Wertheimer SP, Ravetch JV 1994. Organization of chromosomes in Plamodium falciparum: a model for generating karyotypic diversity. Parasitol Today 10: 114-117.

MacDaniel JP, Dvorak JA 1993. Identification, isolation and characterization of naturally occurring Trypanosoma cruzi variants. Mol Biochem Parasitol 57: 213222.

Marretto JPM, Andrade SG 1994. Biochemical behavior of Trypanosoma cruzi strains isolated from mice submitted to specific chemotherapy. Rev Soc Bras Med Trop 27: 209-215.

Murta SMF, Romanha AJ 1998. In vivo selection of a population of Trypanosoma cruzi and clones resistant to benznidazole. Parasitology 116: 165-171.

Pacheco RS, Brito CMM 1999. Reflections on the population dynamics of Trypanosoma cruzi: heterogeneity versus plasticity. Mem Inst Oswaldo Cruz 94: 199-201.

Postan M, McDaniel JP, Dvorak JA 1986. Trypanosoma cruzi: constancy of clone pathogenicity for inbred mice during long-term in vitro maintenance. Trans $R$ Soc Trop Med Hyg 80: 659-662.

Revollo S, Oury B, Laurent J-P, Barnabé C, Quesney V, Carrière V, Noël S, Tibayrenc M 1998. Trypanosoma cruzi: impact of clonal evolution of the parasite on its biological and medical properties. Exp Parasitol 89: 30-39.

Santos FR, Pena SDJ, Epplen JT 1993. Genetic and population study of a Y-linked tetranucleotide re- peat DNA polymorphism with a simple non-isotopic technique. Hum Genet 90: 655-656.

Tibayrenc M, Ayala F 1988. Isozyme variability in Trypanosoma cruzi, the agent of Chagas disease: genetical, taxonomical and epidemiological significance. Evolution 42: 277-292.

Toledo MJO, Gasperi MV, Marques de Araújo S, Lana M 1995. Berenice 62 and Berenice 78 strains of Trypanosoma cruzi: comparison of their susceptibility to benzidazole. Mem Inst Oswaldo Cruz 90 (Suppl.): 201.

Toledo MJO, Guilherme ALF, Silva JC, Gasperi MV, Mendes AP, Gomes ML, Araújo SM 1997. Trypanosoma cruzi: chemotherapy with benznidazole in mice inoculated with strains from Paraná state and from diferent endemic areas of Brazil. Rev Inst Med Trop São Paulo 39: 283-290.

Toledo MJO, Lana M, Bahia MT, Carneiro CM, Alves CF, Martins HR, Tibayrenc M, Tafuri WL 2000. Evaluation of chemotherapy with benznidazole and itraconazole in mice infected with different Trypanosoma cruzi clonal genotypes. Mem Inst Oswaldo Cruz 95 (Suppl. II): 314.

Voller A, Bidwell DE, Bartlett A 1976. Enzyme immunoassays in diagnostic medicine. Theory and practice. Bull WHO 53: 55-65.

Winker P, Britto C, Borges-Pereira J, Cardoso MA, Oeleman W, Morel CM 1994. Use of a simplified polymerase chain reaction procedure to detect Trypanosoma cruzi in blood samples from chronic chagasic patients in a rural endemic area. Am J Trop Med Hyg 51: 771-777. 
1012 Susceptibility to Benznidazole in Isolates of T. cruzi • VM Veloso et al. 